\title{
Dialogue Culture and Its Relationship with \\ Psychological Compatibility of Students of "Learning Disabilities" Course at the College of Education, Najran University
}

\author{
Dr. Naseh Hussen Salem (Corresponding author) \\ Department of Special Education, College of Education, Najran University, Saudi Arabia \\ Tel: 966-538-676-618Ｅ-mail: nasehhusen@yahoo.com
}

Dr. Gomaa Farouk Helmi

Department of Special Education, College of Education, Najran University, Saudi Arabia

Tel: 966-569-323-424Ｅ-mail: gomaa3769@yahoo.com

Received: February 12, 2016 Accepted: March 1, $2016 \quad$ Published: March 2, 2016

doi: 10.5296/jsss.v3i2.9019 URL: http://dx.doi.org/10.5296/jsss.v3i2.9019

\begin{abstract}
The study aimed to identify the nature of the relationship between dialogue culture of college of education students at Najran University and their psychological compatibility. In addition, it aimed to define the impact of age variable on this culture. It also tried to explore the possibility of predicting the level of these students' psychological compatibility by variables of dialogue culture. The study instruments involved a scale for measuring university students' dialogue culture prepared by the researchers in addition to a test for psychological compatibility prepared by Shoqir (2003). The sample consisted of all students enrolled in "Learning Disabilities" course in the second semester of the academic year 2014/2015. Findings showed a significant positive correlation $(\alpha=0.01)$ between students' dialogue culture and all dimensions of their psychological compatibility. There were differences between 19-year old students group and 22-year old students group in favor of the latest due to cognitive, affectional and behavioral levels of dialogue culture. Findings also indicated that the three dimensions of dialogue culture (cognitive, affectional and behavioral) could predict the psychological compatibility levels of students of "Learning Disabilities" course at the college of education.
\end{abstract}


Keywords: dialogue culture, Psychological compatibility, Learning disabilities, Najran University

\section{Introduction}

Man nowadays lives in very complex circumstances. Rapid and successive change has become a prominent key feature of the era in various fields. The impact of all this has become clear in the life of all individuals of varied ages. Along with the complexity of life in this era, the multiplicity of visions, the contradiction in opinions, and the difference in views emphasizes the individual's needs for dialogue to argue with others, discuss views and ideas, and resolve what problems he encounters. Hence, the acquisition of dialogue culture becomes important. Training on this culture must be an educational aim that permeates all activities and educational programs. It should be the interest of any educational system. Furthermore, dialogue is one of the most important life issues as we need capable individuals who can analyze the various views, participate in dialogue, and use the style of conviction. Most of our daily life activities and the conflicts they impede are in urgent need for dialogue in order to achieve our contradicting goals and benefits. Dialogue, as Habeeb (1998) points out, is necessary for maturation and wonders how man can maturate, understand himself, identify his points of weakness and strength, understand from whom to learn if he departs people and does not negotiate with them. Dialogue stems its great importance from the fact that human social entity can not be achieved without the existence of others who are different. Dialogue is a process that involves conversation among individuals or groups despite their different attitudes and ideas for the sake of knowledge and understanding exchange. Therefore, man will not achieve his human self and produce knowledge without concourse, dialogue and creative communication with others. In addition, dialogue is one mean for transferring ideas and exchanging views to fulfill specific aims. In brief, by dialogue, university student can explore himself, his capabilities and others. He can also increase his knowledge, develop his will and frees it from the concentration on and care for himself to care and feel sympathy with others.

\subsection{Aims of the Study}

The study aims to:

1) Identify the nature of the relationship between dialogue culture of the College of Education students enrolled in "Learning Disabilities" course at the college of Education at Najran University and their psychological compatibility, in addition to age impact.

2) Predict the level of the psychological compatibility of students enrolled in "Learning Disabilities" course at the college of Education at Najran University via some variables of dialogue culture.

3) Develop dialogue culture scale of all dimensions for university students.

4) Present recommendations, guidance, and applications for subsequent studies and research with regard to the findings of the present study to be used in the field of special education.

\subsection{Statement of the Study and Questions}

The statement of the study can be stated as: 
1) What is the relationship between dialogue culture of students enrolled in "Learning Disabilities" course at the college of Education at Najran University and their psychological compatibility?

2) Is it possible to predict the level of psychological compatibility of students enrolled in "Learning Disabilities" course at the college of Education at Najran University via some variables of dialogue culture?

3) What is the impact of age on the dialogue culture of students enrolled in "Learning Disabilities" course at the college of Education at Najran University?

\subsection{Importance of the Study}

Dialogue is very important for effective interaction among individuals. It is a cooperation between debaters to reach reality, discover what is hidden for each, and follow the sound reasoning to reach the right. Dialogue is a human demand represented in the use of constructive dialogue styles to fulfill the need to integrate in community and communicate with others. It accomplishes balance between the human needs for independence, participation, and interaction with others, (Bin Hameed, 1996: 7). Allaboodi (2003:7) points out that developed countries used to specify scientific departments at universities to teach the arts of communication and dialogue. They also have specified separate courses at schools to teach dialogue skills, rules, etiquette, principles, and arts of verbal communication. Dialogue culture has an importance for youth in general and university ones more specifically as they are bully and like to own, have control and prove themselves, which in turn yields many problems if constructive dialogue is missed.

\subsection{Terms of the Study}

Dialogue culture: Dialogue culture is a style that combines debaters addressing a specific issue where each one presents evidence and arguments that support his point of view. At the end, they all reach a common opinion and constants in a frame of cordiality and mutual respect (Gomaa, 2010:164). In the present study dialogue culture is a set of intellectual rules and principles in addition to behavioral standards in which individuals believe when they communicate with others. It also involves etiquette and urbanization differences that drive the individual to more decency and estimation of others, which establishes an amount of social acceptance and skip problems of social contexts.

Psychological compatibility: Compatibility means harmony and convergence. It is the opposite of dissonance and collision. Compatibility is a guided conduct to overcome obstacles and difficulties, mechanisms, which the human learns in his struggle with life and through which he seeks to satisfy his needs and motives and release his stress to achieve the same sense of balance and satisfaction. It is a personal matter, in which individual's experience and surrounding attitudes operate, (AL-Anani, 2005). Psychological compatibility has many definitions among which is the person's ability to fulfill his needs and meet his psychological and social requirements through a harmonized relationship with the environment where he lives, (Wolmen, 1973). The researchers, in turn define psychological compatibility as those responses that indicate the sense of education college students of social, personal, affectional, family, and health (physical) satisfaction and general psychological compatibility, which is indicated by the total degree that a student gets on the scale. It 
involves many dimensions like social, personal, affectional, family, and health (physical) compatibility.

Social compatibility: Social compatibility represents the individual's ability in an effective social participation, his sense of social responsibility, his compliance to the values of the society in which he lives. It is his sense of his value and effective role in community development, his ability to achieve the sense of belonging and loyalty to the group around him. Furthermore, it is his engagement in constructive social competitions with others and his ability to establish positive good relations. It also represents his attention to others' rights in a mutual trust and respect. In addition, it is his sense of happiness and gratitude because of his belonging to a group and occupying a distinguished status through the social cooperative work he performs.

Personal and affectional compatibility: Personal and affectional compatibility means the individual's ability to accept himself and has a sense of self- satisfaction. It is his ability to achieve his needs by effort excretion and continuous work. It is his sense of strength and courage. It is also his sense of his own value and his value in life. Furthermore, it is his being free from neurotic disorders and his enjoyment of an affectional balance and psychological calmness.

Family Compatibility: Family compatibility expresses the individual's enjoyment of a happy life within the family that appreciate, love and care about him. It is his sense of his vital role within this family and level of appreciation by family members. Understanding is the dominant style among them in addition to what his family provide him with to satisfy his needs, solve his problems, achieve greater self-confidence and understanding and help to establish mutual affection and loving relationship.

Health compatibility (physical): It is the enjoyment of the individual with good health, which is free from physical, mental and affectional illness in addition to his acceptance of and satisfaction with his appearance. It is his being free from organic problems, his sense of psychological comfort towards his abilities and potentials. Furthermore, it is his enjoyment of sound senses, his tendency to vigor and vitality most of the time, his ability to move and be balanced and his safety and concentration with continuity in vigor and work without exhaust or weakness in his task, (Shoqir, 2003). Therefore, psychological compatibility can be defined operationally in the present study as "the degree that is got by study sample of the college of education at Najran University who enrolled in "Learning Disabilities" course on the four scale dimensions".

\subsection{Manifestations of Psychological Compatibility}

Psychologists like Mousa (2001) and Abed Almotajali (2004) have defined a set of attributes by which personality can be judged whether relatively compatible or not. These attributes include good self-image, taking responsibility, success at work, self-realization, sense of happiness, psychological comfort, crises confrontation, making realistic goals, noble ethics, social compatibility, ability to sacrifice, safety of physical diseases, and affectional equilibrium.

\subsection{Compatibility Cofactors}

Psychological compatibility is a state, in which the individual achieves his own abilities, can 
overcome normal difficulties in life, and work productively and fruitfully. Fahmi (1998) and Abed Almotajali (2004) have pointed to a set of specific cofactors for a person to be compatible such as fatalism, affectional stability, primary and secondary needs-satisfaction, peaceful, self-acceptance, scientific thinking and horizon breadth, self- identification, flexibility, and availability of a set of values and social positive attitudes.

\section{Previous Studies}

\subsection{Studies Addressing Dialogue}

Abdel Azim (2004) aimed at developing the cognitive and performance skills of dialogue. The study concluded the effectiveness of the proposed program in the development of the cognitive side of dialogue and all related skills. It also asserted the effectiveness of the program to develop the students' performance in dialogue skills. The study recommended the need to raise students' awareness of the importance of dialogue and take care of the development of its skills through the habit formation and practice, and increase the ways of dialogue activities that arise students' desire to perform and practice it efficiently. Gomaa (2008) aimed to clarify the meaning of dialogue culture and its importance for students at the college of education. It also aimed to determine the ethics and rules of dialogue to be adhered to while debating and to monitor the reality of dialogue culture of students at the college of education and the extent of their commitment in their conduct and practice through various life activities. The study also aimed to highlight the factors that hinder dialogue culture in Egyptian society and the resulting conflicts and disagreements. In addition, it investigated the views of students at the college of education regarding the benefit of the curriculum and academic activities in the development of culture dialogue to define the educational contributions that help deploying the dialogue culture among student teachers to be transferred to coming generations. The study concluded the students' awareness of the importance of dialogue culture for them and for their society in general. It indicated the reluctance of individuals and society to debate because they do not have the skills of the effective dialogue. Ahmad (2010) aimed to determine the necessary dialogue skills for university students, identify their empowerment level of these skills, in addition to diagnose the weakness points in students' performance of these skills. The study concluded a list of dialogue skills that are necessary for university students. It also pointed out the university students' low possession level of dialogue skills. The study recommended the necessity of dialogue skills and ethics inclusion in university courses. It also urged researchers to prepare programs for the development of university students' dialogue skills.

\subsection{Studies that Tackled Psychological Compatibility}

Al-Tahhan (1990) studied the relationship between self-concept, on one hand and academic achievement and psychological compatibility on the other hand. The total number of study sample was (100) students from the college of education in United Arab Emirates University. Findings showed positive correlations between the total self-concept and academic achievement, and between self-concept and psychological compatibility. Al-Sabban (1999) studied the psychological and personal problems and the need for psychological counseling among some students at Umm Al Qura University in the College of Education for Girls in Jeddah. The sample consisted of (270) students of various academic disciplines. Findings showed an existence of psychological problems among female students such as anxiety, 
tension, and shame. Al-Akayshi (2003) studied students' compatibility in the university environment, affectional intelligence and future concern. The study was carried out on a sample of (400) university students. It concluded that university students suffer from future concern and enjoy compatibility and affectional intelligence. It also revealed a significant correlation between the three research variables. Al-Dhabe and Al Saud (2004) studied the alienation problem among a sample of Saudi female university students in light of globalization era. The study sample consisted of (50) female students from the colleges of Education, Arts, Computer, languages and Translation who were between 18-29 years old. Findings showed that the sense of meaningless factor headed the sources of alienation among female students, followed by the sense of social helplessness, then the sense of isolationism, grief, utilitarian, lack of standards, and cultural spacing. Al-Akayshi (2004) studied mental health and its relationship with affectional intelligence among young female university students at the College of Education for Girls at Baghdad University. The sample included (100) participants of departments that represent the college of education for the first and fourth stages with (50) students from the first stage for all departments, and 50 students from the fourth stage. Findings showed significant differences in university students' affectional intelligence. There were significant differences on students' psychological health and affectional intelligence measures in accordance to the educational stage variable in favor of the fourth stage. Furthermore, there was a statistically significant relationship between the mean scores of students due to the mental health and affectional intelligence variables. Bobsheet (2008) studied the academic problems that students at the college of Applied Studies and Community Service at King Faisal University face. The study sample consisted of (432) female students in various academic disciplines. Results revealed that high school academic stream (literary/ scientific) in addition to the accumulative average were the least affecting variables in female students' understanding of the importance of the academic problems.

\subsection{Hypotheses of the Study}

The study aimed to test these hypotheses:

1). There is a statistically significant correlation between the dialogue culture as perceived by students enrolled in "Learning Disabilities" course at the college of Education at the University of Najran and the level of their psychological compatibility.

2) It is possible to predict the level of psychological compatibility of students enrolled in "Learning Disabilities" course at the college of Education at the University of Najran via variables of dialogue culture.

3) There are significant differences between means of students enrolled in "Learning Disabilities" course at the college of Education at the University due to age variable on dialogue culture scale.

\section{Methodology}

\subsection{Study Approach}

This study was based on the descriptive analytical approach, which describes the reality of dialogue culture of students enrolled in "Learning Disabilities" course at the college of Education at Najran University and analyzes its points of strength and weakness for the sake 
of developing such type of culture.

\subsection{Study Population}

The population of the present study consisted of all students enrolled in "Learning Disabilities" course at the college of Education at Najran University.

\subsection{Study Sample}

The sample involved all students enrolled in "Learning Disabilities" course at the college of Education at the University. Their total number was (200) students. They are all between (1823) years old.

\subsection{Study Instrument}

Two main instruments were used, namely Dialogue Culture Scale and Psychological Compatibility Scale.

\subsubsection{First: Dialogue Culture Scale}

It was developed through these steps.

a) A thorough review of the theoretical framework with regard to dialogue culture in general and more specifically among university students.

b) Revision of previous scales related to dialogue culture.

c) Development of the initial version of the scale.

d) Conducting an exploratory study.

e) Judging the scale.

f) Testing the efficiency of the scale by checking its validity and reliability.

g) Developing the scale in its final version.

\subsubsection{Determination of the Scale's Dimensions}

In light of the previous steps, the sub dimensions of the dialogue culture scale could be determined in three ones namely, the cognitive, affectional, and behavioral (verbal/nonverbal) dimensions.

a) The cognitive dimension, which means systematic dialogue and stereotypical thinking of an individual that make him ready to respond to dialogue through his related knowledge, information, and ideas.

b) The affectional dimension that is the component that refers to the individual's feelings. It involves his tendencies, attitudes, readiness and motivational and affectional aspects towards dialogue that indicate his point of view, feelings and readiness for dialogue. It also includes his psychological traits that distinguishes the debating individual and qualifies him for success.

c) The behavioral dimension that refers to the individual's conduct and method with which he will deal in a particular talk context throughout his noticeable and measurable behavioral manifestations when debating and interacting with others. These manifestations include:

Verbal behavior, which is the individual's conduct during dialogue like the diversification of his intonation and stress according to the dialogue context in addition to listening.

Non-verbal behavior that involves individual's body language, gesture, visual communication, and face expressions. 


\section{$\Lambda$ Macrothink}

\subsubsection{Development of the Primary Version of the Scale}

The primary version of the scale consisted of (60) items distributed to three main dimensions. Items from (1-15) were for the cognitive dimension. Items from (16-40) were specified for the affectional, whereas items from (41-60) constituted the behavioral dimension. Each item had five responses. A degree was assigned for each response staring from (5) for the highest and ending with (1) for the lowest.

Efficiency of the scale, which included its reliability, validity, and internal consistency among its contexts and dimensions. The researchers presented the primary version of dialogue culture scale to eleven arbitrators of faculty members at the departments of psychological health, counseling, and special education at Najran and Cairo Universities. The jury also included learning disabilities schoolteachers. The scale, as was presented to the jury included a definition for each dimension of dialogue culture and the (60) items. Arbitrators were asked to revise the exactness of contexts that represent dialogue culture dimensions, their distribution to the dimensions, the linguistic accuracy, and the responses that fulfill them. Arbitrators were also requested to determine the contexts appropriate for measuring each dimension and delete the inappropriate one according to the specific definition of each dimension. For each context and response to be considered in the final version, it should be agreed on by eight arbitrators at least. To make any modification or deletion, agreement of two arbitrators was enough to do that. Arbitrators were also asked to judge the correction key. Their agreement percentage was (90-100\%). Results of judgment indicated that the scale was suitable for the study aim and the sample age. Its items were fit for the operational definition and so it had a good degree of content validity.

\subsubsection{Reliability of the Study Scale}

Scale reliability was verified through a set of statistical programs known as SPSS in the following ways:

1) Use of Cronbach Alpha, which is a statistical tool sensitive for sample errors. It is used to measure according to the consistency of the scale and expresses one content. Correlation coefficient of the scale by Alpha was $(0.7201)$ and significant at $(\alpha=0.01)$. Alpha coefficients for the scale dimensions are shown in the table (1) below.

Table 1. Alpha coefficients for dialogue culture scale dimension

\begin{tabular}{lc}
\hline Dimension & Alpha Cronbach Coefficient \\
\hline Cognitive dimension & 0.7101 \\
Affectional dimension & 0.7208 \\
Behavioral dimension & 0.7309 \\
The whole scale & 0.7201 \\
\hline
\end{tabular}

2) Scale reliability by split half method

Scale reliability was tested by split half method. Coefficient was $(0.81)$ which is a high one.

3) Scale reliability by test and retest 


\section{Macrothink}

The researchers repeated the application after twenty-one days from the first application. General reliability coefficient was (0.90) which was a high coefficient and asserted its reliability.

4) Internal consistency

The researchers also calculated the correlation between the degree of each context and the degree of the dimension to which it belonged to indicate the extent of consistency between the degree of each context and the dimension degree to which it belonged (which is consistent with the present study sample). Five items were deleted because they were insignificant. Therefore, the total number of item in the final version was (55) items.

\subsubsection{Validity of the Scale}

The following methods were used to ascertain the validity of study scale:

\section{1) Apparent validity}

It is the validity of the general appearance or appropriateness of the scale for the tested persons. It can be recognized through the applicability of items to the aim it is going to test in terms of its suitability for students' age and education levels, (Imam, 1992:24). In addition, apparent validity for dialogue culture scale was recognized through its fitness for the sample's age and cultural environment. The five responses were congruent with the five levels of dialogue culture, the equality of items length in each dimension and the absence of problem during application

\section{2) Content (arbitrators) validity}

The scale was presented to eleven arbitrators who were of expertise in psychological health, counseling, and special education to consult their views regarding the validity of context content and the effectiveness of what they were developed for. Then the researchers registered arbitrators' views and judgments related to each dimension and the scale as a whole. Therefore, percentage of arbitrators' agreement on the scale's contexts was the criteria for judging the content validity.

3) Ways of scale correction

Responses to dimensions were corrected according to a five-point scale. The response "too much" was given (5) and the response "much" was given (4). Degree (3) was assigned for "moderate" response while (2) and (1) were assigned for little and "too little" respectively.

\subsubsection{Second: The Scale of Psychological Compatibility}

Shoqir (2003) mainly developed the psychological compatibility scale that involved (80) items aiming at compatibility identification. Items were developed into four dimensions namely, the personal (affectional), health (physical), family, and social compatibility. Items were to be answered by "yes, no", and sometimes "neutral". The least degree was (zero) and the highest was (160). Its validity and reliability were tested on a sample of Saudi males that consisted of (100) individuals. Its validity was asserted by the configuration method and discriminatory validity. Its reliability was checked by test, retest and split half method. The coefficient was between (0.69 and 0.81). 


\section{Findings}

\subsection{First: The First Hypothesis Findings and Discussion}

The first hypothesis stated, "there is a statistically significant correlation between dialogue culture as perceived by students enrolled in "Learning Disabilities" course at the college of Education at Najran University and their psychological compatibility level including personal, health, social, family, and general psychological compatibility. The following sub hypotheses could be derived:

1) There is a positive correlation between dialogue culture of students enrolled in "Learning Disabilities" course at the college of Education at Najran University and their personal compatibility.

2) There is a positive correlation between dialogue culture of students enrolled in "Learning Disabilities" course at the college of Education at Najran University and their health compatibility.

3) There is a positive correlation between dialogue culture of students enrolled in "Learning Disabilities" course at the college of Education at Najran University and their family compatibility.

4) There is a positive correlation between dialogue culture of students enrolled in "Learning Disabilities" course at the college of Education at Najran University and their social compatibility.

5) There is a positive correlation between dialogue culture of students enrolled in "Learning Disabilities" course at the college of Education at Najran University course and their general psychological compatibility.

To test the correctness of these hypotheses, Pearson Correlation Coefficient was calculated between the study sample raw grades on the scale of dialogue culture and their grades on the scale of psychological compatibility. Results are illustrated in table (2).

Table 2. Pearson Correlation Coefficient between the dimensions of dialogue culture and psychological compatibility $(\mathrm{N}=150)$

\begin{tabular}{lllll}
\hline $\begin{array}{l}\text { Psychological } \\
\text { Compatibility } \\
\text { Dimensions }\end{array}$ & \multicolumn{2}{c}{ Dialogue Culture Dimensions } & \\
\hline Personal & $* * 0.0445$ & $* * 0.415$ & $* * 0.311$ & $* * 0.311$ \\
Health & $* * 0.870$ & $* * 0.812$ & $* * 0.712$ & $* * 0.712$ \\
Social & $* * 0.561$ & $* * 0.716$ & $* * .0 .614$ & $* * 0.614$ \\
General Compatibility & $* * 0.716$ & $* * .665$ & $* * 0.461$ & $* * 0.461$ \\
\hline
\end{tabular}

Correlation Coefficient $=0.254$ at $(\alpha=0.01)$; ** Correlation is significant at $(\alpha=0.01)$.

Correlation Coefficient $=0.194$ at $(\alpha=0.05)$; ${ }^{*}$ Correlation is significant at $(\alpha=0.05)$.

Table 2 reveals that there was a positive correlation $(\alpha=0.01)$ between dialogue culture of 
students at the Faculty of Education at Najran University who were enrolled in "Learning Disabilities" and all dimensions of their psychological compatibility.

\subsection{Second: The Second Hypothesis Findings and Discussion}

The second hypothesis stated, "The level of psychological compatibility of students at the Faculty of Education at Najran University who are enrolled in "Learning Disabilities" course can be predicted through the variables of dialogue culture. To check this hypothesis and to understand the impact of dialogue culture on the levels of psychological compatibility, multiple regression analysis was used taking into account that variables of dialogue culture were independent and the levels of psychological compatibility were dependent. Table 3 shows these results.

Table 3. F. ratio for the predictability of psychological compatibility by dialogue culture

\begin{tabular}{llllll}
\hline Source of variation & Sum of squares & D. F. & Average of squares & F. ratio & $\boldsymbol{\alpha}=$ \\
\hline Regression & 117.869 & 1 & 117.869 & 4.088 & 0.05 \\
The rest & 8602 & 298 & 28.867 & & \\
Total & 8720.197 & 299 & & & \\
\hline
\end{tabular}

Table 3 indicates that F. ratio was significant when $(\alpha=0.05)$ which means that dialogue culture could predict the psychological compatibility. That is, there was a relationship between dialogue culture and psychological compatibility.

Table 4 illustrates the results that were related to the variables that were the most contributing ones in the prediction of psychological compatibility.

Table 4. Contribution of dialogue culture to psychological compatibility levels

\begin{tabular}{cccc}
\hline $\begin{array}{c}\text { Source of } \\
\text { variation }\end{array}$ & $\begin{array}{c}\text { Simple } \\
\text { correlation }\end{array}$ & $\begin{array}{c}\text { Multiple } \\
\text { correlation }\end{array}$ & $\begin{array}{c}\text { Percentage of } \\
\text { contribution }\end{array}$ \\
\hline 1 & 0.12 & 0.14 & 1.4 \\
\hline
\end{tabular}

Table 5. Multiple regression for the highest dialogue culture variables predictability of the levels of psychological compatibility

\begin{tabular}{lllllll}
\hline Dimensions & $\begin{array}{l}\text { Simple } \\
\text { correlation }\end{array}$ & $\begin{array}{l}\text { Multiple } \\
\text { correlation }\end{array}$ & $\begin{array}{l}\text { Reg. } \\
\text { weights }\end{array}$ & $\begin{array}{l}\text { Contrib. } \\
\text { percentage }\end{array}$ & F. & $\boldsymbol{\alpha}=$ \\
\hline Cognitive & 0.116 & 0.014 & 0.268 & 1.40 & 2.021 & 0.05 \\
Affectional & 0.114 & 0.012 & 0.254 & 1.20 & 2.18 & 0.05 \\
Behavioral & 0.111 & 0.011 & 0.248 & 1.11 & 2.006 & 0.05 \\
whole scale & 0.113 & 0.0113 & 0.260 & 1.13 & 2.15 & 0.05 \\
\hline
\end{tabular}


Table 5 reveals that:

1) The cognitive dimension of dialogue culture could predict the levels of psychological compatibility of students enrolled in "Learning Disabilities" course at the college of education more than other variables.

2) The affectional dimension of dialogue culture predicts the levels of psychological compatibility of students enrolled in "Learning Disabilities" course at the college of education.

3) The behavioral dimension of dialogue culture predicts the levels of psychological compatibility of students enrolled in "Learning Disabilities" course at the college of education.

4) All dimensions of dialogue culture predict the levels of psychological compatibility of students enrolled in "Learning Disabilities" course at the college of education.

\subsection{Third: The Third Hypothesis Findings and Discussion}

The third hypothesis stated, "There are significant differences between the mean scores of students enrolled in "Learning Disabilities" course at the college of Education at Najran University due to age variable on the scale of their dialogue culture". To test the correctness of this hypothesis, variance analysis of factorial design for the interaction of age variable (19 and 22 years) was used to identify the effect of the chronological age on the levels of dialogue culture. Findings are illustrated in Table 6.

Table 6. F. ratio for the differences between the levels of dialogue culture dimensions in light of students' age

\begin{tabular}{|c|c|c|c|c|c|c|c|}
\hline Dimensions & $\begin{array}{l}\text { Source } \\
\text { variation }\end{array}$ & $\begin{array}{l}\text { Sum } \\
\text { squares }\end{array}$ & D.F. & $\begin{array}{l}\text { Average } \\
\text { squares }\end{array}$ & of & $\begin{array}{l}\text { F. } \\
\text { ratio }\end{array}$ & $\alpha=$ \\
\hline \multirow[t]{3}{*}{ Cognitive } & Between groups & 99.727 & 2 & 49.863 & & --- & --- \\
\hline & Within groups & 2323.67 & 297 & 7.824 & & 6.373 & 0.01 \\
\hline & Total & 2423.397 & 299 & ---- & & --- & --- \\
\hline \multirow[t]{3}{*}{ Affectional } & Between groups & 82.887 & 2 & 41.443 & & --- & --- \\
\hline & Within groups & 3886.030 & 297 & 13.048 & & 3.167 & 0.05 \\
\hline & Total & 3968.97 & 299 & ---- & & --- & --- \\
\hline \multirow[t]{3}{*}{ Behavioral } & Between groups & 245.297 & 2 & 122.603 & & --- & --- \\
\hline & Within groups & 6474.990 & 297 & 28.535 & & 4.297 & 0.05 \\
\hline & Total & 8720.197 & 299 & --- & & --- & \\
\hline
\end{tabular}

Table 6 reveals that F. ratio for the differences among the three levels of dialogue culture (cognitive, affectional, and behavioral) in light of the age of students enrolled in "Learning Disabilities" course at the college of education was significant at $(\alpha=0.01)$ and $(\alpha=0.05)$. To understand the direction of these differences, Scheffe test was used for the differences between (19) years old group and (22) years old group. 
Table 7. Scheffe Test for the direction of differences between students' in both age groups

\begin{tabular}{llllll}
\hline Dimensions & Groups & M. & 19 years group & 22 years group & $\boldsymbol{\alpha}=$ \\
\hline Cognitive & 19 years & 24.05 & 1.17 & 1.27 & 0.05 \\
& 22 years & 25.52 & --- & 0.100 & 0.05 \\
Affectional & 19 years & 30.04 & 0.010 & 1.85 & 0.05 \\
& 22 years & 30.05 & --- & 1.11 & 0.05 \\
Behavioral & 19 years & 43.50 & 0.200 & 2.010 & 0.05 \\
& 22 years & 43.70 & --- & 1.81 & 0.05 \\
\hline
\end{tabular}

Table 7 proves that there were significant differences between (19) years old group and (22) years group regarding the three levels of dialogue culture of students enrolled in "Learning Disabilities" course at the college of education in favor of (22) years old group as it had higher mean.

\section{Discussion of the Findings}

Findings of the present study showed that there was a positive correlation between dialogue culture and the level of psychological compatibility of students enrolled in "Learning Disabilities" course at the college of education in all dimensions. This result corroborates what most studies have concluded regarding the negative correlation between dialogue culture and the sense of insecurity, lack of care and anxiety, such as Jeffry (2007) and Patterson (2002). Dialogue culture is linked to a set of concepts such as permission, coexistence, respect, patience, moderation, esteem. It is also related to moderation and social peace that does not only mean war goals as a political phenomenon but also expresses a social one that has an intrinsic level which is peace with one's self in addition to an extrinsic level which is peace with others, state and community. Both levels are crucial to create a peaceful world that excludes the manifestations of violence, oppression and fear (Bela \& Patrick, 2005). The danger of dialogue absence in modernized societies lies in the rapid change, the many developments that societies witness in all fields of life, the disparity of individuals' abilities to cope, which produce a set of negative points in light of dialogue absence, (Allaboodi, 2003).

Furthermore, communities' development and civilizations are measured by the extent of dialogue prevalence among their individuals and their ability in the dialogue, which creates clear channels of understanding among all. Dialogue culture is a means for free expression. It represents the middle circle among individuals. It depends on opinion freedom, and self-defense right in a modernized approach (Gomaa, 2008). In addition, Game et al. (2008) mention that tyranny and authoritarianism are social diseases that lead to sense of oppression, accompanied by deviant behaviors where honesty shrinks, faith retreats, courage and compassion disappear, and lying and hypocrisy dominate.

In conclusion, dialogue culture is a complicated composite that extends to include numerous cognitive, affectional, and behavioral requirements, which all integrate to shape the individual's features of dialogue culture. Therefore, the researchers divided dialogue culture 
into three main components or dimensions that involved cognitive, behavioral, and affectional dimensions. Under dimension lied a set of skills, items, or manners that were developed after accessing the related literature and the previous studies, whether Arabic or English ones, that the researchers could consult.

\section{Conclusion}

Depending on what has been mentioned, the researchers conclude the importance for the youth between (19-22) years old to acquire the dialogue culture because of its role in their personal, health, family and social psychological compatibility. Thus, If acceptance, knowledge, understanding of others, tolerance, equality and democracy prevail the dialogue culture, students will acquire and learn the psychological compatibility. However, if it is abnormal and dominated by rejection, ignorance, lack of understanding of others, cruelty, discrimination, and authoritarian, acquisition and learning of psychological compatibility will be hindered. Hence, The main aim of the present study is the scientific contribution in the understanding of the relationship between dialogue culture and the acquisition of students aging (19-22 years) of psychological compatibility, on one hand and the relationship between the acquisition of compatibility levels and university students' age, on the other hand.

\section{Recommendations}

In light of the findings of the present study, researchers recommend:

1) The need to raise parents' awareness of the importance of dialogue culture that help family members to pursue ways of good interaction among them, how to avoid abnormal family operations and solve problems that the family may encounter by dialogue.

2) The need to provide guidance programs to increase parents' awareness of youth phase and its importance, the most important traits and features that characterize this stage, and how to deal with these young people to pass this stage peacefully and grow in the right direction.

3) The need to provide university students with guidance and training programs that aim to develop basics of good dialogue so that they can comply with themselves and their community.

4) The need for media to pay attention to programs specified to the importance of dialogue and etiquette to increase the awareness of the whole society of the importance of dialogue culture and its effects on youth psychological compatibility (personal, social, health, and family), which we desperately need in light of life variables.

\section{Proposed Research}

1) Dialogue culture and its relationship with high school students' psychological compatibility.

2) Ways of parental treatment and its relationship with children dialogue culture at various age levels.

3) A training program to develop dialogue and its effect on the quality of university students' life.

4) The effectiveness of a counseling program to increase mother's tolerance and its effect on children's psychological compatibility. 


\section{Macrothink}

Journal of Social Science Studies ISSN 2329-9150 2016, Vol. 3, No. 2

5) Relationship between family and school atmospheres and children acquisition of dialogue culture.

6) A counseling program for the development of dialogue culture and its effect on elementary children psychological compatibility.

7) Studying the psychological structure of university students of high and low dialogue culture.

\section{Acknowledgments}

The research is funded by the Deanship of Scientific Research at Najran University and holds number NU/SHED/14/30. The researchers of the present study are grateful to the Deanship of Scientific Research at Najran University for funding this research and for every effort and assistance, they offered. The researchers are also indebted to those people who took part in this study for everything they did for the success of this work.

\section{References}

Abdel Azim, R. (2004). A Proposed Program for the Development of Dialogue Skills in Arabic Language among Students at the college of Media in Light of Linguistic Communication Approach, (unpublished MA. thesis), Girls College, Ain Shams University, Egypt.

Abed Almotajali, M. R. (2004). Anxiety is one of the Varied Styles of Upnormal Adaptation, Qafilah Journal, 7.

Ahmed, S. M. H. (2010). Dialogue Skills Necessary for Female Students at the College of Education at Um Al Qura University in Light of Era Variables and Innovations and Measuring their Empowerment of These Skills. Journal of Reading and Knowledge, 99.

Al- Akayshi, B. A. J. (2003). Compatibility in University Environment and its Relationship with Future Anxiety, (unpublished Ph.D. dissertation), Al- Mustansiriya University, Iraq.

Al- Akayshi, B. A. J. (2004). Psychological Health and its Relationship with Affectional Intelligence of University Youth at the College of Education for Girls, Journal of the College of Education and Psychology, 10(3).

Al Anani, H, A. (2005). Psychological Health (3rd edition) Amman: Al- Fikr house for printing and distribution.

Al-Dhabe, T. Y., \& Al Saud, J. F. (2004). Factorial Study of Alienation among a Sample of Saudi University Female Students in Light of Globalization. Journal of the College of Education, 5(2).

Al- Tahhan, M. K. (1996). Principles of Psychological Health (1st ed.) Dubai: Dar Al-Qalum.

Allaboodi, M. A. (2003). Dialogue: its Techniques, Strategies and Learning Styles, Cairo: Wehbeh Bookshop.

Bela, H. B., \& Patrick, M. J. (2005). Dialogue as a means of collective communication. New York: Kluwer Academic.

Bin Hameed, S. A. (2003). Dialogue, Knowledge Profile, Dialogue Culture and Violence, Journal of Knowledge, 101, Ministry of Education, KSA.

Bobsheet, J. I. (2008). Academic Problems Facing Students at the College of Applied Studies and Community Service at King Faisal University as Perceived by themselves. College of 


\section{Macrothink}

Education, King Faisal University, 20(1), 177.

Game, A., \& Metcalfe, A. (2008). Significance of Dialogue in Learning and Teaching. Educational Theory, 58(3), 343-356. http://dx.doi.org/10.1111/j.1741-5446.2008.00292.x

Gomaa, F. A. (2008). Dialogue Culture among College of Education Students in Egypt: A Field Study. Journal of Studies in Higher Education, 18.

Gomaa, M. H. A. (2010). Islamic Educational Employment of Dialogue Culture with the Other: Proposed Vision. Journal of Reading and Knowledge, 1030(1), 150-190.

Habeeb, S. (1998). Art of Dialogue (3rd ed.), Cairo: Dar Al- Thaqafah.

Jeffrey, T. (2007). Creating a Culture of Thinking and Dialogue at Home. Gifted Child Today, 30(4), 21-25.

Mousa, M., Abed Al Hameed, S., \& Abed Al Salam, F. (1984). Scale of Psychological Health for Matures (1st ed.), Studies and Research Series: Saudi Arabia: Um Al Qura University.

Patterson, J. 1. (2002). Personality Style Consideration in Effective Dialogue. Journal of Aggression, 4(1), 37.

Shoqir, Z. M. (2002). The Scale of Psychological Compatibility (1st ed.). Cairo: Dar Al-Nahdhah for Printing, Publishing, and Distribution.

Wolmen, B. B. (1973). Dictionary of Behavioral Science, New Jersey: Mac- Millan Co.

\section{Copyright Disclaimer}

Copyright for this article is retained by the author(s), with first publication rights granted to the journal.

This is an open-access article distributed under the terms and conditions of the Creative Commons Attribution license (http://creativecommons.org/licenses/by/3.0/). 